\title{
The earthquake cycle and its role in the long-term deformation of the continental lithosphere
}

\author{
Wayne Thatcher \\ U.S. Geological Survey, Menlo Park, California, U.S.A.
}

\begin{abstract}
An understanding of the cyclic deformation related to large crustal earthquakes constrains the rheological stratification of the lithosphere and illuminates the link between present-day movements and late Cenozoic tectonic processes. Comparison of model predictions with geodetic measurements of the earthquake deformation cycle imply largely elastic behavior for the seismogenic upper crust but cannot distinguish between brittle and ductile rheologies for the mid and lower continental crust. Joint use of geodetic measurements of inter-earthquake shear straining and paleomagnetic rotation data in the same region provides a means of relating tectonic processes occurring over different timescales and permits an estimate of the increment of permanent deformation that accumulates in each seismic cycle. Observations and inferences on the average duration of the seismic cycle in active regions provide a unique perspective on the degree to which relatively short ( 100 year or less) seismicity catalogues may be representative of the long-term upper crustal deformation rate.
\end{abstract}

\section{Introduction}

The quasi-periodic recurrence of large earthquakes and the cyclic build-up and release of elastic strains in the brittle upper crust (see fig. 1) provide constraints on lithospheric deformation processes that complement those provided by other methods. Inter-earthquake crustal straining (fig. 1a)) is caused by deformation occurring beneath the seismogenic layer and so supplies information on the constitutive behavior of the lower crust/upper mantle lithosphere (e.g., see Savage, 1983a; Thatcher, 1986; Tse and Rice, 1986). Geodetic measurements document slight imbalances between accumulated and relieved strains that, when summed over many cycles, produce permanent deformations that can often be preserved in the geological record (Thatcher, 1984b). The earthquakes themselves generate crustal strains, and if the available inventory of seismic events is sufficiently complete this earthquake record can be applied to determine rates of upper crustal straining which may be compared with other measures of lithospheric deformation rate (Kostrov, 1974; Molnar and Deng, 1984; Holt et al., 1991).

The purpose of this paper is to briefly review how an understanding of the earthquake cycle can shed light on the long-term deformation of the continental lithosphere.

I first describe the cyclic crustal deformation in the vicinity of strike-slip faults and discuss the classes of models consistent with available data.

I next compare geodetic measurements of coseismic and inter-earthquake crustal movements with paleomagnetic observations of vertical-axis rotations to illustrate the connection between cyclic movements and permanent deformation. Finally, I describe how the duration of seismic cycle influences the precision with which historical and instrumental earthquake catalogues may be used to compute seismic strain rates that are representative of long-term upper crustal deformation rates. This brief review relies on a small number of illustrative examples and is necessarily incomplete. Further details can be found in the references cited in the text. 


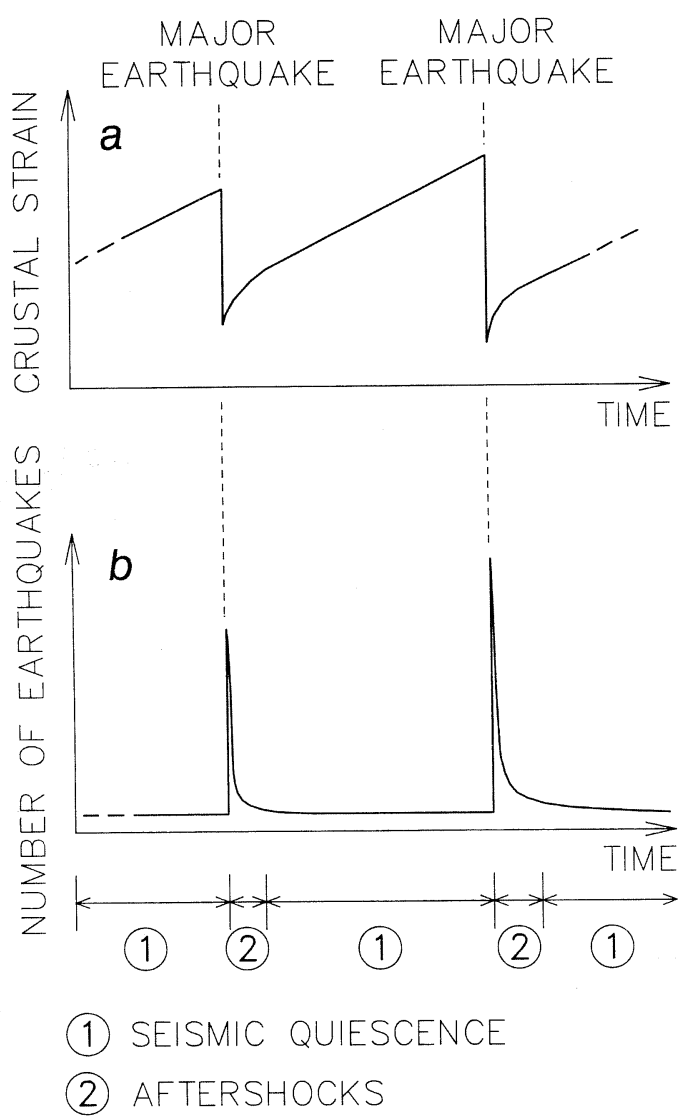

Fig. 1. The earthquake cycle. a) Alternating slow increase in crustal strain in-between large earthquakes and the abrupt strain drop occurring at the time of the earthquake. b) Earthquake activity versus time, with major earthquakes followed by an aftershock sequence and very low levels of seismicity until the occurrence of the next major event.

\section{Earthquake deformation cycle}

The cycle of earthquake strain accumulation and release can be observed using repeated geodetic survey measurements, and relevant data have been gathered at both strike-slip and reverse-faulting plate boundary deformation zones. Here I illustrate general features of the cycle using data and models relevant to the San Andreas and other strike-slip faults. Interested readers may refer to Savage (1983b), Thatcher (1984a), Thatcher and Rundle (1984), and Savage and Thatcher (1992) for discussion of the subduction boundary deformation cycle.

Figure 2 shows the fault geometry and figure 3 summarizes coeseismic, postseismic, and interseismic surface deformation that occurs near strike-slip faults. Coseismic movements depend on the amount of fault slip and the depth to which it extends, and deformation can be modeled well using elastic dislocation theory (see Okada, 1985). The mechanisms responsible for postseismic transient movements and steady interseismic deformation are uncertain. Two contrasting models have been proposed (fig. 4). In the first, the depth of coseismic faulting, $D$, is much less than the thickness, $H$, of the elastically strong lithospheric plate. Postseismic movements are caused by episodic slip immediately downdip of the coseismic rupture segment, while interseismic deformation is due to steady aseismic fault slip at greater depths. For the thin lithosphere model, $D / H \simeq 1$, and bulk flow of the underlying weak layer accounts for inter-earthquake deformation in the elastic lithosphere.

It is surprising that these two contrasting models for the cycle produce movements at the earth's surface that are observationally indistinguishable (Savage and Prescott, 1978; Thatcher, 1983; Savage, 1990). Figure 5 schematically illustrates the model-predicted inter-earthquake shear strain rates at 5 successive time intervals between two large earthquakes. In these models

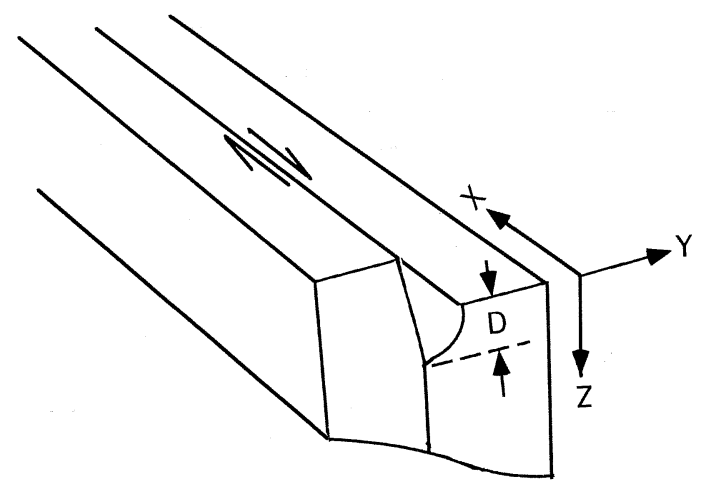

Fig. 2. Strike-slip faulting geometry, showing fault slippage extending from the surface $Z=0$ to depth $Z=D$. Fault is two-dimensional, with slip extending indefinitely along the $x$-axis. 

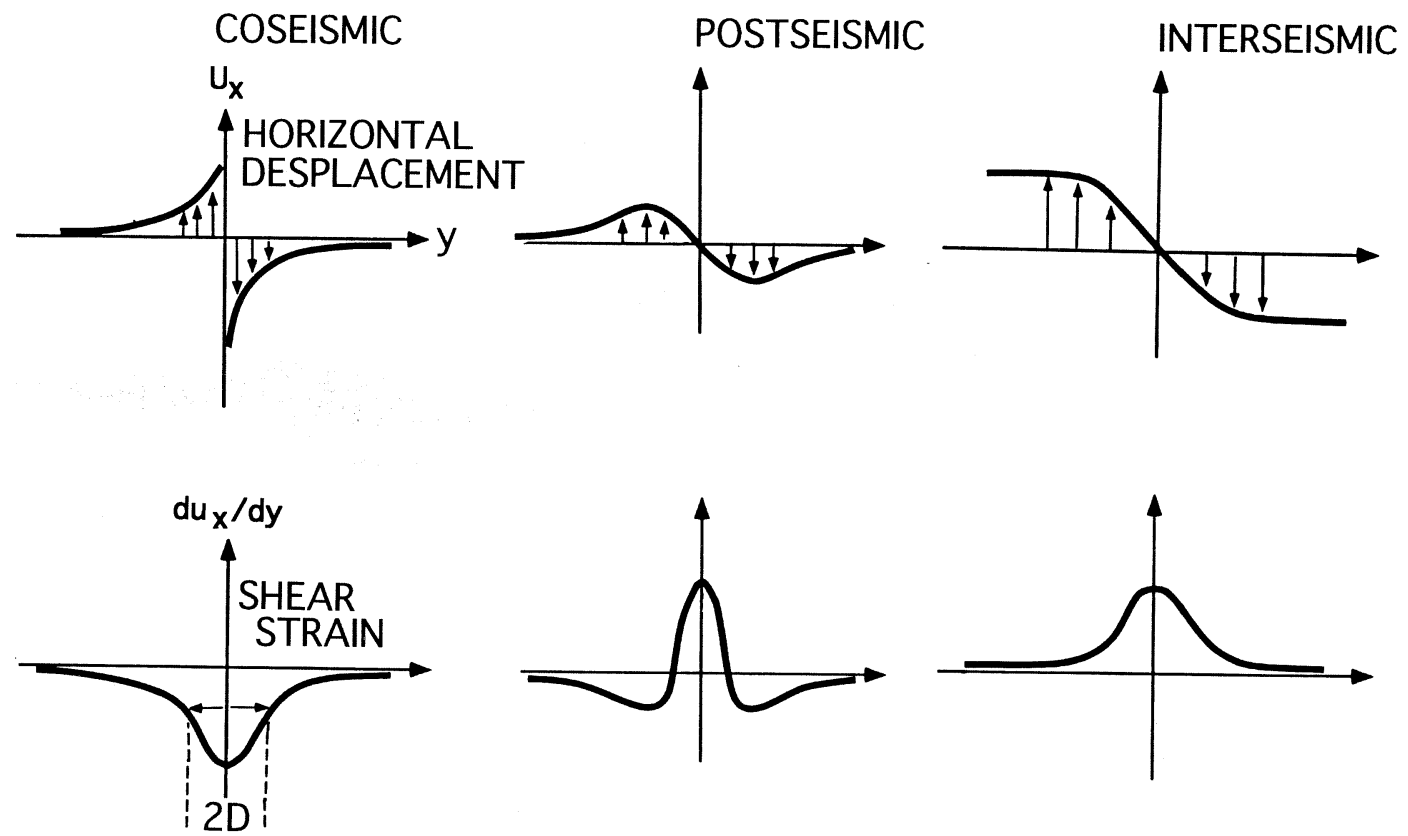

Fig. 3. Strike-slip earthquake deformation cycle, showing horizontal displacement and shear strain component parallel to fault strike referred to coordinate axes shown in fig. 2 .

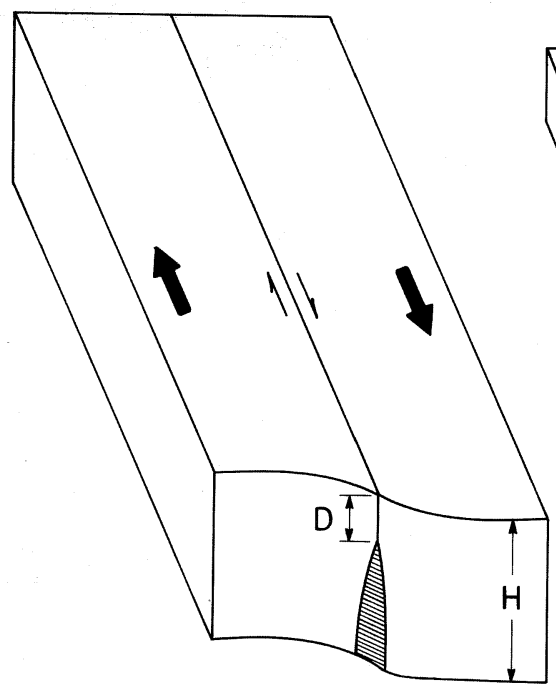

THICK

LITHOSPHERE MODEL

$\mathrm{D} / \mathrm{H}<<$ I

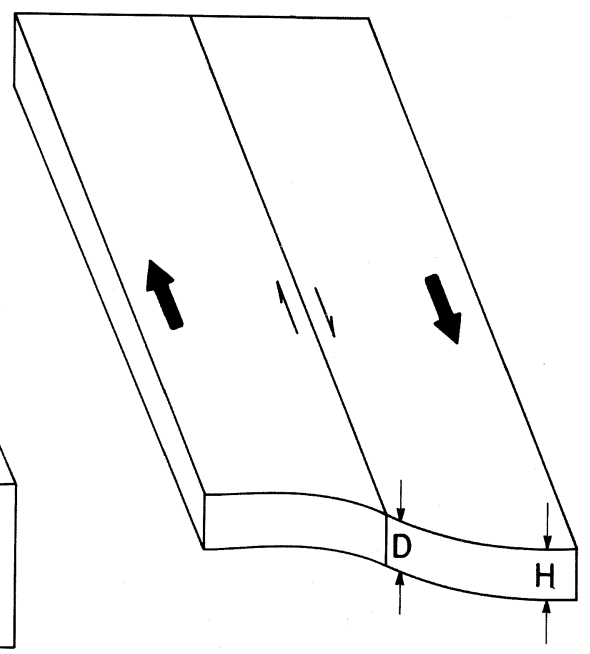

THIN

LITHOSPHERE MODEL

$\mathrm{D} / \mathrm{H} \simeq \mathrm{I}$

Fig. 4. Two models for the earthquake deformation cycle on a strike-slip fault. Depth of coseismic slip $=D$, thickness of elastic lithosphere $=H$. 
(a)

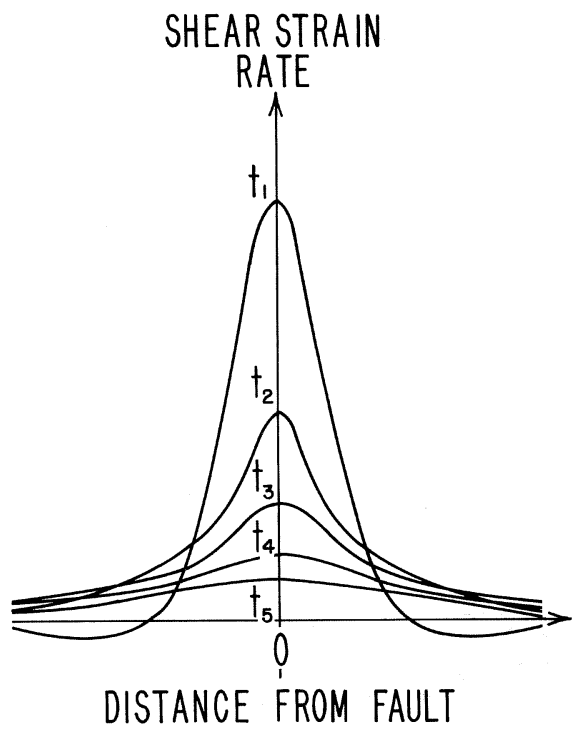

(b)

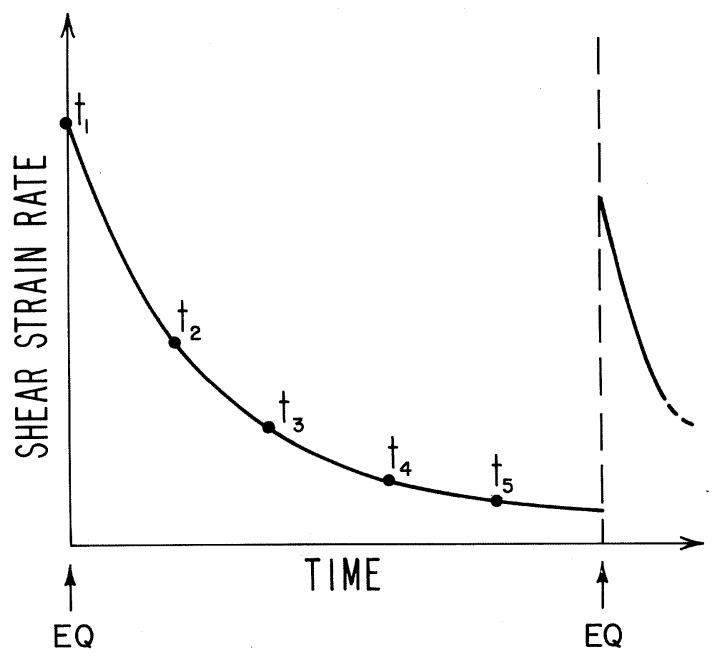

Fig. 5. Surface deformation predicted for models of fig.4. a) Shear strain rate versus perpendicular distance from fault for 5 successive times following earthquake. b) Shear strain rate near fault versus time (Thatcher, 1983).

there is no clearly defined separation between postseismic and interseismic movements, but rate changes are largest early in the cycle and nearly constant rates prevail later. Time constants for the stress relaxation process depend on either a slip relaxation time (thick lithosphere model) or bulk viscosity (thin lithosphere model). Shorter relaxation times concentrate transient movements early in the cycle, longer times cause strain rate to decline through much or all of the cycle.

Limited observational evidence supports the general features sketched in fig. 5. The spatial distribution of interseismic shear straining (fig. 6) has a bell-shaped pattern that mimics the expected pattern shown in fig. 4 and 5 . The half- width of the observed profile is $(20 \div 30) \mathrm{km}$, which reflects both the depth-extent of coseismic fault slip or inter-earthquake fault locking, about $(10 \div 15)$ $\mathrm{km}$ (e.g., Thatcher, 1975), and the surposed effects of strain accumulation on several sub-parallel strike-slip faults of the San Andreas system.

Figure 7 shows a secular decline in shearstrain rates near the 1906 and 1857 earthquake ruptures on the San Andreas fault that is similar to that predicted by the thick and thin lithosphere models (fig. 5b)). Note that although it may be questionable to lump together data from these two great earthquakes on a single plot, tha main features of postseismic rate decline are demonstrated for the northern San Andreas fault.

Since deformation measurements cannot be used to distinguish between competing models of the earthquake cycle, other studies bearing on the nature of the brittle-ductile transition and fault continuity into the lower crust are needed to provide firm constraints. Mapping of the deep levels of now inactive fault zones provides one line of evidence bearing on the mechanical behavior of the ductile lithosphere, and figure 8 summarizes the salient features of one such mapping study by Bak et al. (1975). The cross-sectional reconstruction (fig. 8, bottom) shows a relatively narrow ductile shear zone in the mid-crust that broadens into a zone of broadly-distributed bulk deformation in the more deeply exposed roots of this transcurrent fault of late Pre-Cambrian age. If these observations are applicable to currentlyactive strike-slip faults they suggest a transition 


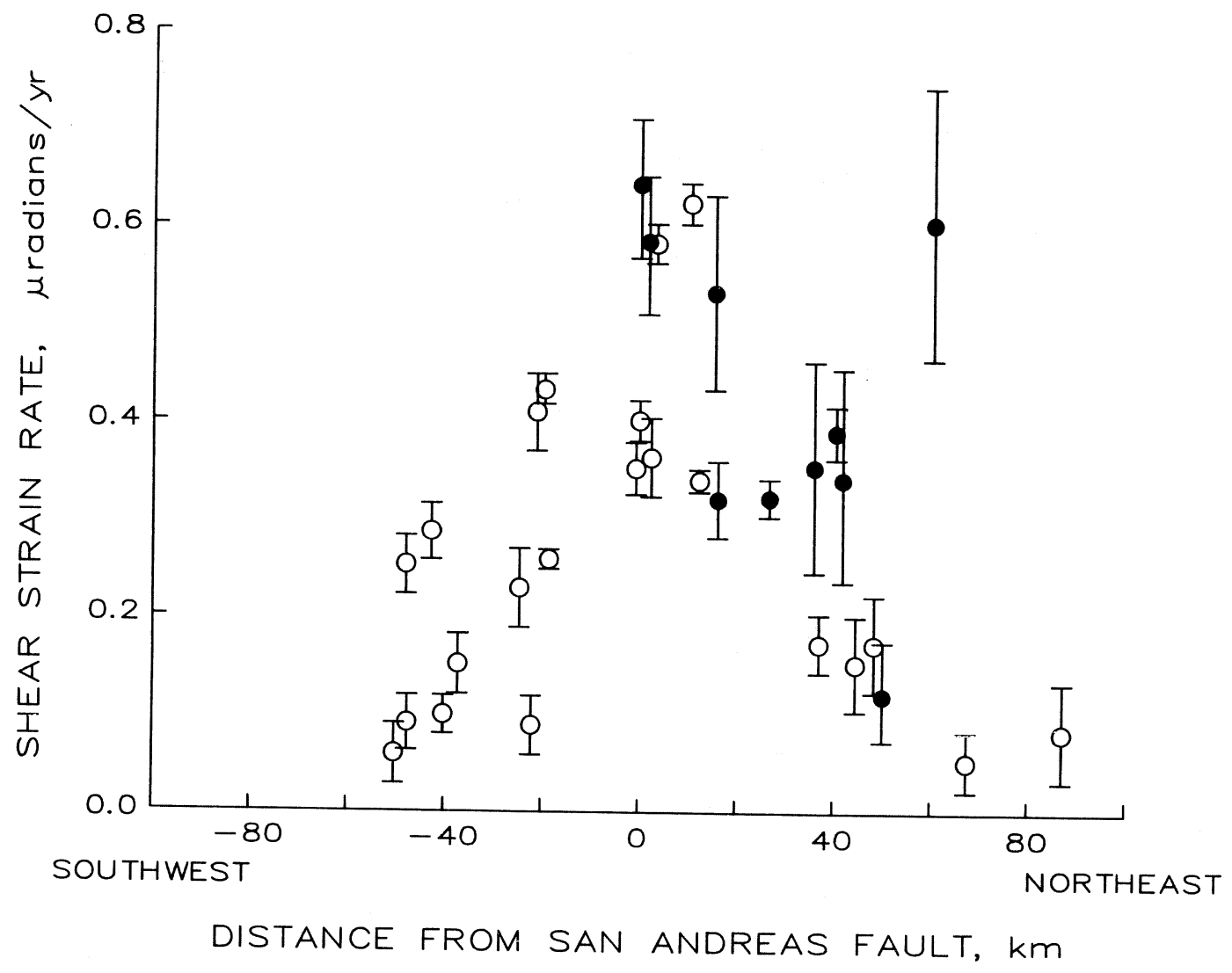

Fig. 6. Shear strain rate versus perpendicular distance from San Andreas fault. Solid circle shows determination from northern California, open circle is determination from southern California (Thatcher, 1990).
One-standard-deviation-error bars are shown for reference.

from narrowly-focussed aseismic slippage immediately beneath the brittle crust to bulk deformation in the lower crust.

\section{Permanent deformation}

Most idealized models of the earthquake deformation cycle, such as those discussed here, assume that inter-earthquake strain accumulation is perfectly balanced by coseismic strain release (viz. fig. 1a)). However, some geodetic measurements (Thatcher, 1984a, 1984b), along with many geological indicators and paleomagnetic measurements suggest significant deviations from this assumed behavior. Figure 9 illustrates how this imbalance occurs in a single cycle, and depending on which phase of the cycle is dominant, permanent deformation features can mimic either the coseismic or interseismic movement patterns. Uplifted late Quaternary and Holocene marine terraces in regions of reverse faulting (Lajoie, 1986) and uplifted and rotated footwall blocks of normal faults (Stein et al., 1988) demonstrate the importance of permanent deformation in dip-slip faulting environments. Here I shall demonstrate how the cyclic imbalance of strain around active strike-slip faults can lead to vertical-axis rotations that may be detected by paleomagnetic methods.

Figure 10 shows the patterns of expected coseismic and interseismic rotations as a function 


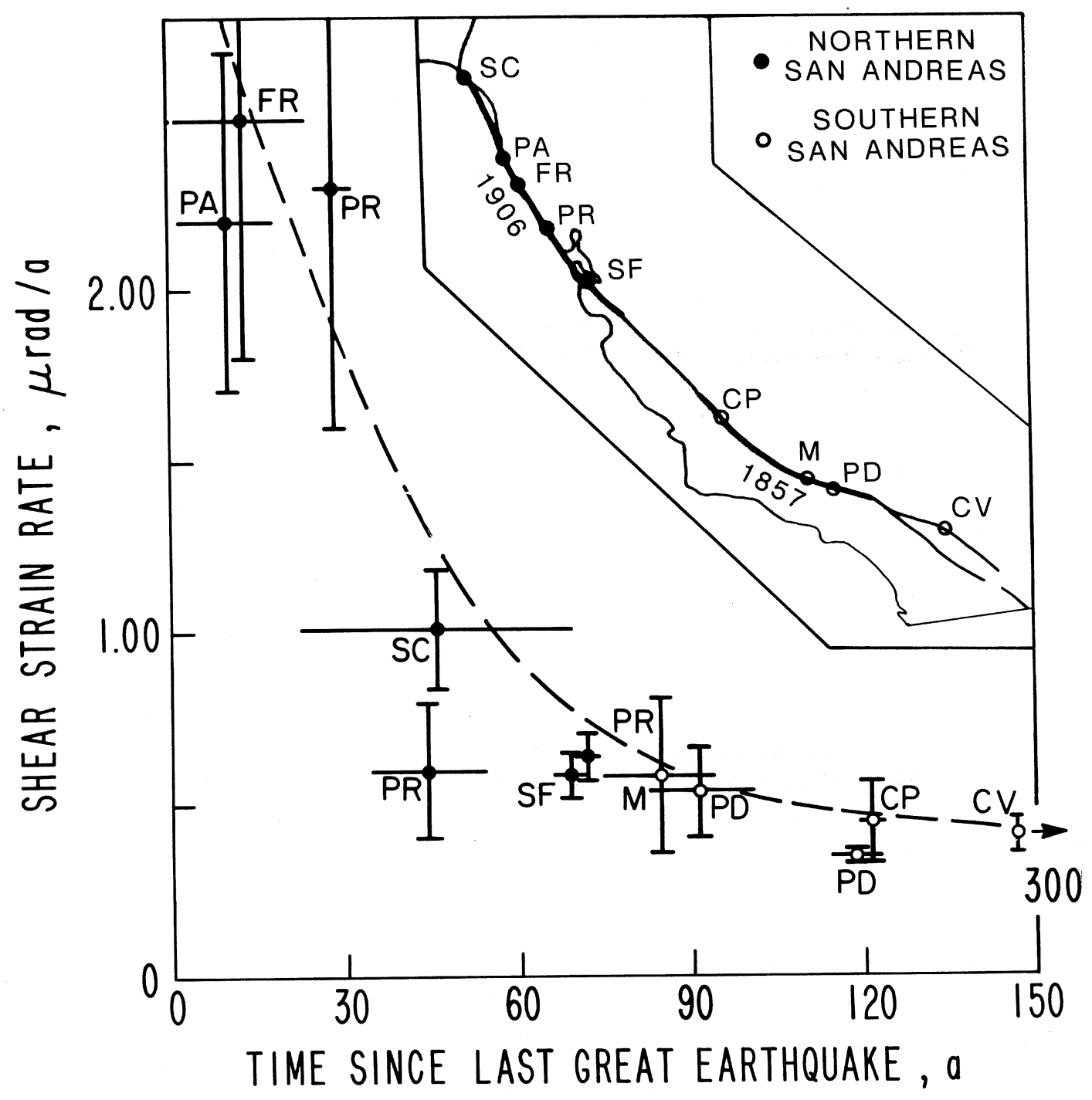

Fig. 7. Shear strain rate versus time since last great earthquake on San Andreas fault, 1906 on the northern San Andreas and 1857 on the southern segment. Inset map shows these segments with heavy solid lines, as well as locations of sites, indicated by letters, where strain rates have been determined. For each data point, vertical bar is one standard deviation error and horizontal line indicates time interval between surveys (Thatcher, 1983).

of distance from an infinitely long vertical strikeslip fault. The rotations occurring within a single cycle are small. Coseismic changes are no more than about $10^{-4}$ radians. Interseismic rates observed in California and New Zealand (fig. 11 and 12) range from about 1 to $6 \times 10^{-7}$ radians/y.
However, if these inter-earthquake rotations were not at least in part reversed by coseismic rotations of opposite sense they would sum to very significant long-term vertical-axis block rotations, since a rate of even $10^{-7}$ radians/y corresponds to $5.8^{\circ}$ of rotation in $1 \mathrm{Ma}$. 


\section{NORDRE STROMFJORD SHEAR BELT W. Greenland}
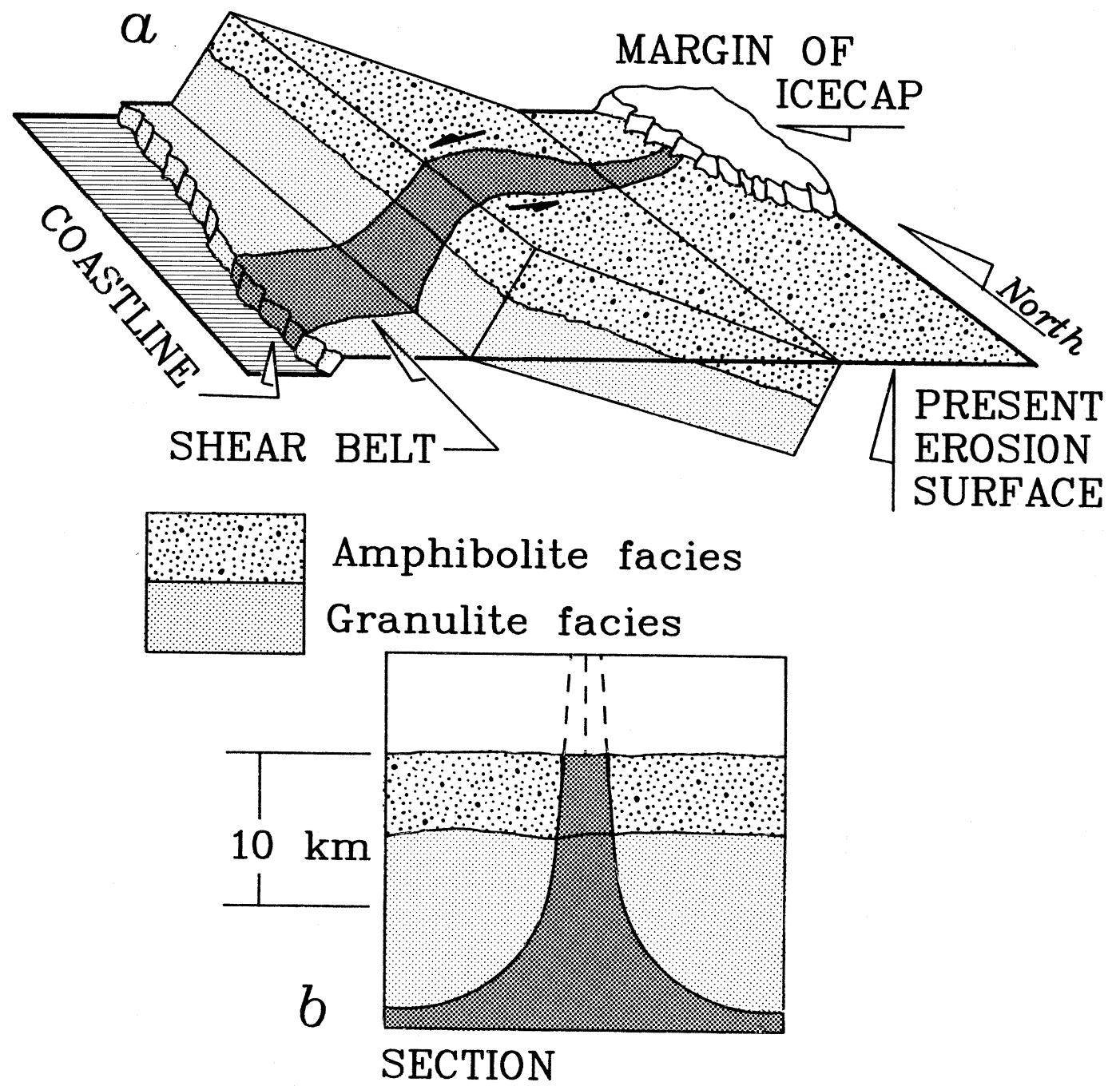

Fig. 8. Schematic block diagram (a) and cross-section (b) of exhumed late Pre-Cambrian ductile shear zone (Bak et al., 1975). 


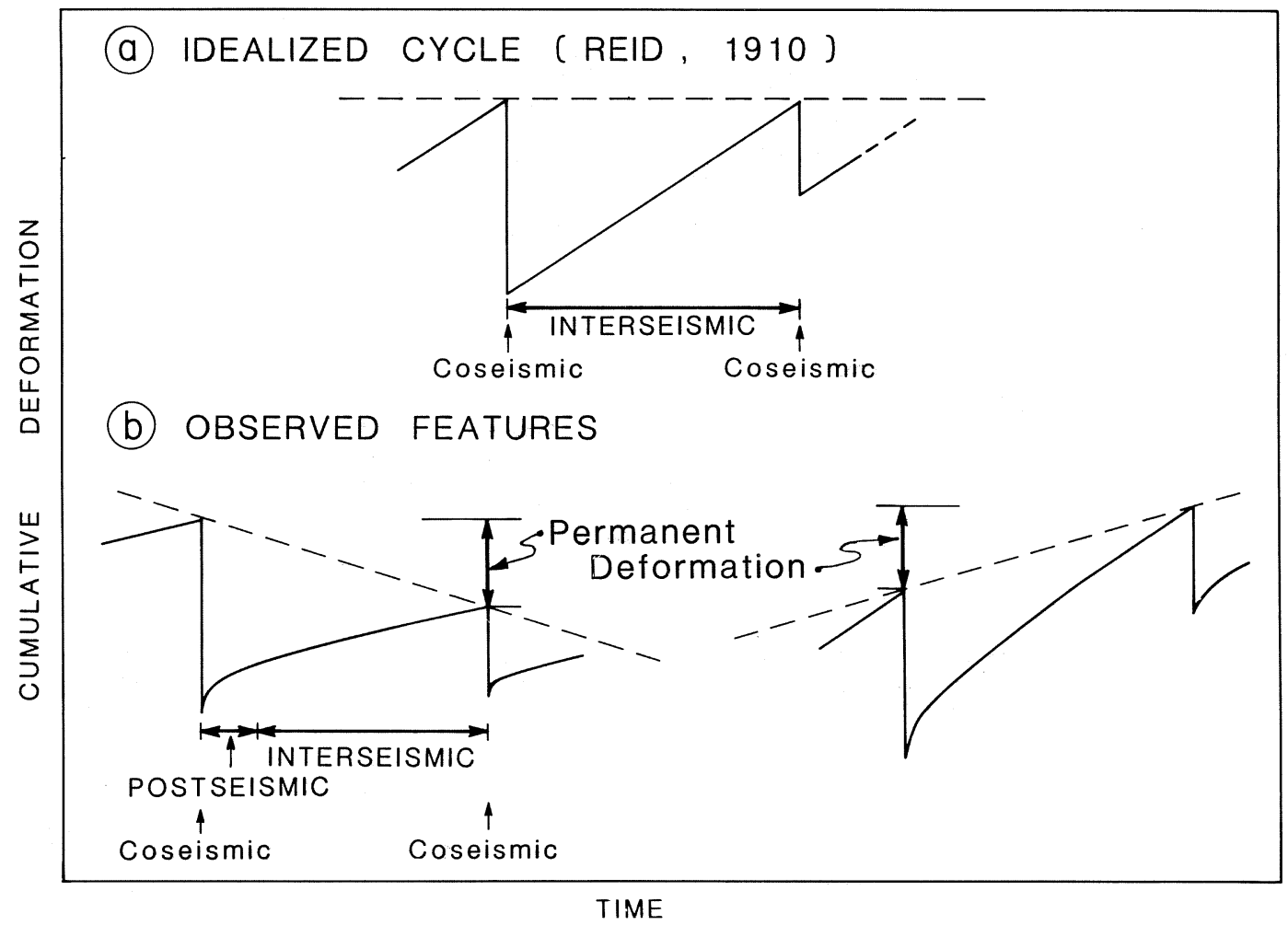

Fig. 9. The earthquake deformation cycle for a) an idealized linear strain build-up model, and b) the case where inter-earthquake straining is not perfectly balanced by coseismic strain release.

INTERSEISMIC

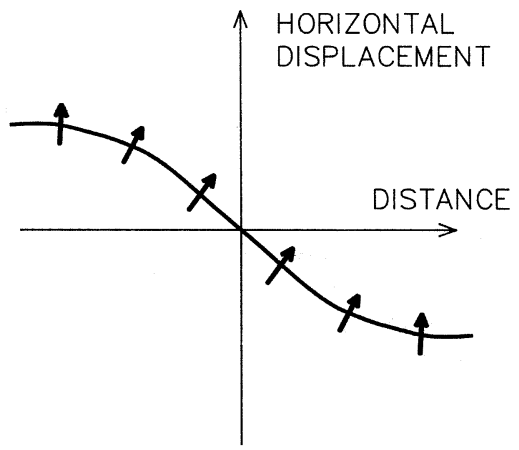

CLOCKWISE
COSEISMIC

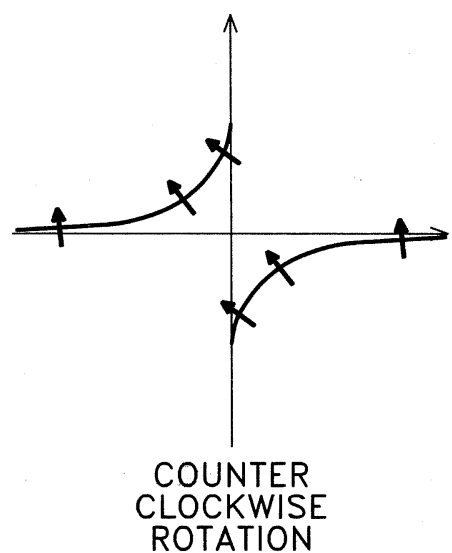

Fig. 10. Horizontal displacement and rotation versus distance from a long vertical strike-slip fault during interseismic and coseismic time intervals. Solid arrows on horizontal displacement curves show schematically how vectors originally alined parallel to the $y$-axis rotated during deformation. 


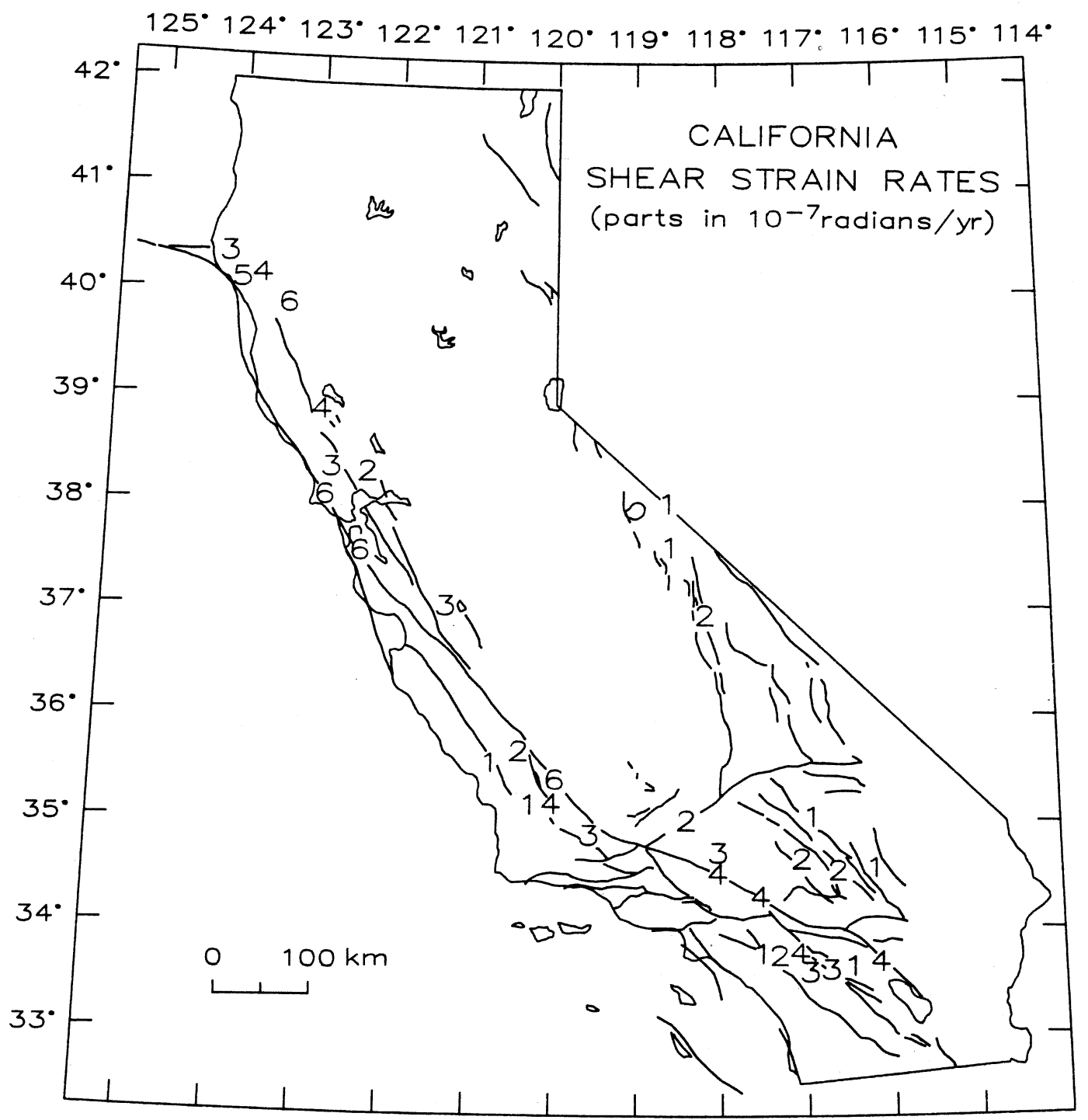

Fig. 11. Interseismic shear strain rates for California in parts in $10^{-7}$ per year.

Comparison of modern, geodetically-determined rotation rates with paleomagneticallyderived late Cenozoic rates provides a powerful means of determining the average imbalance between inter-earthquake and coseismic rotations in strike-slip faulting environments. Figure 13 illustrates the contrasting behavior of two regions, the North Island of New Zealand and the
San Francisco Bay area of northern California. The results from New Zealand indicate average clockwise rotation rates of $(4 \div 8)^{\circ} / \mathrm{Ma}$ in rock ranging in age from 4 to $20 \mathrm{Ma}$ (Walcott, 1984). In contrast, volcanic rocks of $6 \mathrm{Ma}$ age in northern California show little evidence of recent rotation, the sole exception being from a sample site lying within an active right-lateral strike-slip 


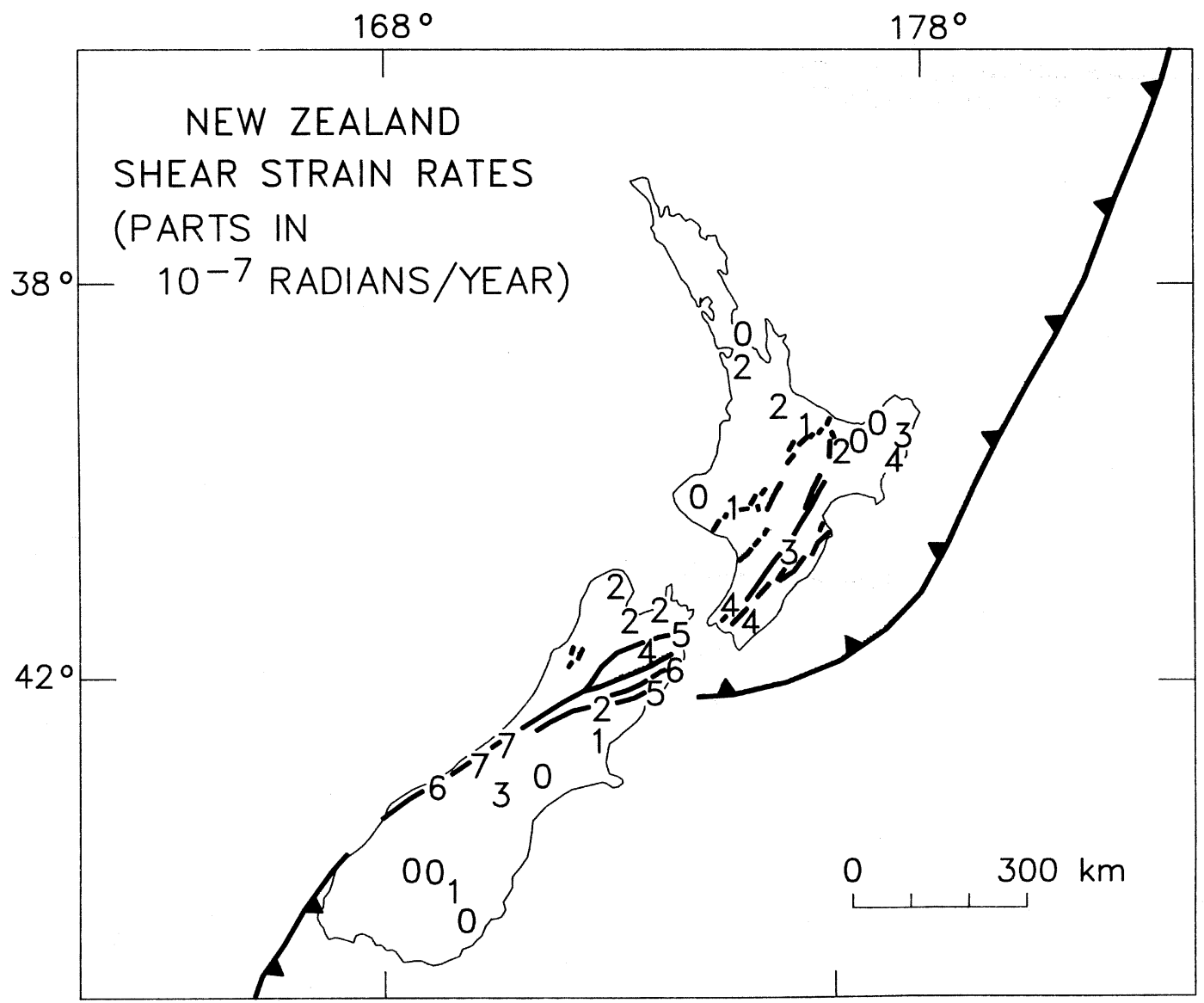

Fig. 12. Interseismic shear strain rates for New Zealand. Major faults and Hikurangi margin subduction zone are shown for reference. Modified from Walcott (1984).

fault zone (Haeussler et al., 1991). Although the origin of the contrasting regional rotation patterns shown in fig. 13 is uncertain, it may reflect the presence, in New Zealand, and the absence, in northern California, of minor faults oriented obliquely to the slip vectors of the major zonebounding faults.

\section{Cycle duration and seismic strain}

As is well known, the reliability of upper crustal strain rates determined using historical or instrumental seismicity catalogues depends upon how well the catalogue represents the long-term deformation rate. Cycle duration (recurrence interval) for the largest earthquakes (generally $M$ 7) xin each study area has a major influence on how representative a catalogue will be. Generally, recurrence interval and maximum earthquake magnitude are correlated with fault slip rate. For example, on major strike strike-slip faults like the southern San Andreas fault, where the slip rate is about $35 \mathrm{~mm} / \mathrm{y}$, events of $M \simeq 8$ recur every 130-400 years (Sieh et al., 1989). In contrast, on continental normal faults like those at the Wasatch Front of the western United States Basin and Range Province, the range-bounding 

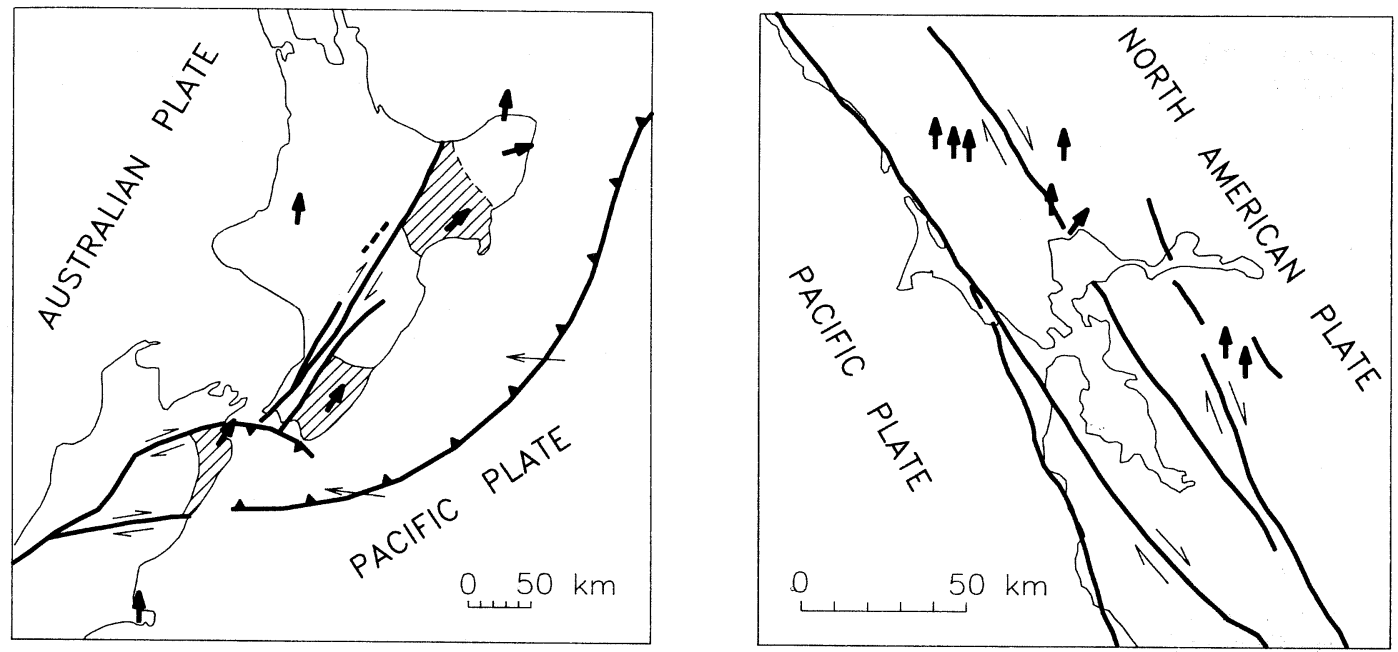

Fig. 13. Paleomagnetically-determined rotations of late Cenozoic rocks in New Zealand (left) and northern California (right). Data from Walcott (1984) and Haeussler et al. (1991).

faults slip at about $1 \mathrm{~mm} / \mathrm{y}$, maximum events are $M \simeq 7 \div 71 / 2$, and recurrence intervals on individual fault segments are 1500-2000 years (Machette et al., 1991).

Although earthquakes with a range of recurrence intervals will occur within a given region, the largest events with the shortest recurrence interval dominate the seismic strain release. For example, throughout much of the Mediterreanean and Middle East, maximum events are $M \simeq 71 / 2$ (Jackson and McKenzie, 1988) and we may infer that deformation is accommodated by slippage on numerous discrete faults with low slip rates and long recurrence intervals. In central Asia, events as large as $M \simeq 8$ occur (Molnar and Deng, 1984) and so longer faults with higher slip rates and shorter recurrence intervals are more important.

Assessing how well a given seismicity catalogue represents long-term deformation patterns is complex in detail but it may be useful to consider a simple idealized case, a region comprised of faults with average recurrence interval $\bar{T}$. If we require that at least one maximum magnitude event occur in a specified region within a catalogue of duration $D$, and the region of interest contains $N$ fault segments capable of sustaining such an event, then $D$ must exceed $\bar{T} / N$ for the catalogue to be representative of the long-term average event rate. Furthermore, since each fault will in general be at a different stage in its seismic cycle, a random time interval of duration $\bar{T} / N$ is likely to be too short to capture a representative sample of maximum magnitude events. The catalogue duration $D_{\min }$ required for reliability will depend on the number of faults $N$ and the statistical variance in the average recurrence interval. Thus, if these factors were known, $D_{\text {min }}$ values could be determined at various confidence levels of catalogue reliability. In the absence of knowledge and for simple illustrative purposes we shall assume $D_{\min }=2 \bar{T} / \mathrm{N}$ here.

In practice, catalogue duration $D$ is fixed and the criterion for reliability translates (for each $\bar{T}$ ) into a requirement on the minimum number of fault segments $N_{\min }$ that must be within the subregion of interest. Typically, even large events are only documented with completeness over the past $\sim 100$ less years or less. Thus, if $D=100$ years, then $N_{\min }$ is only 6 for $\bar{T}=300$ years but increases to 40 for $\bar{T}=2000$ years.

Thus, in regions like the Mediterranean and the Basin and Range Province, where slip rates on individual faults are low, maximum event magnitudes are about $M 7.5$ and seismic strain rates must be averaged over many faults seg- 
ments and large regions to obtain representative long-term average rates. In California and parts of central Asia the shorter average recurrence intervals of $M 8$ earthquakes would permit reliable results to be obtained with averaging over smaller regions and fewer fault segments.

\section{REFERENCES}

BaK, J., J. Grocott, J.A. Korstgard, K. Sorenson, D.F. NASH and J. WATTERSON (1975): Tectonic implications of Precambrian shear belts in western Greenland, Nature, 254, 566-569.

Haeussler, P.J., R.E. Wells, J.W. Hillhouse, A. SARnaWoJCICKI and W. THATCHER (1991): Are there vertical axis rotations in the San Francisco Bay region? Implications from paleomagnetic studies of the 6 Ma Roblar tuff, EOS Transactions A.G.U., 72, 125.

Holt, W.E., J.F. Ni, T.C. WAllace and A.J. HaINes (1991): The active tectonics of the eastern Himalayan syntaxis and surrounding regions, J. Geophys. Res., 96, 14595 14632.

JACKSON, J. and D. MCKENZIE (1988): The relationship between plate motions and seismic moment tensors, and the rates of active deformation in the Mediterranean and Middle East, Geophys. J. R. Astron. Soc., 93, 45-73.

Kostrov, V.V. (1974): Seismic moment, and the energy of earthquakes, and the seismic flow of rock, Izv. Acad. Sci. USSR Phys. Solid Earth, 1, 23-44 (in Russian).

LAJOIE, K.R. (1986): Coastal tectonics, in Active Tectonics, (National Academy Press, Washington, D.C.), pp. 95124.

Machette, M.N., S.F. Personius, A.R. Nelson, D.P. SCHWARTZ and W.R. LUND (1991): Segmentation models and Holocene movement history of the Wasatch fault zone, Utah, J. Struct. Geol., 23, 137-149.

Molnar, P. and Q. DENG (1984): Faulting associated with large earthquakes and the average rate of deformation in central and eastern Asia, J. Geophys. Res., 89, 6203-6228.

OKADA, Y. (1985): Surface deformation due to shear and tensile faults in a half-space, Bull. Seismol. Soc. Am., 75, 1135-1154.

SAVAGE, J.C. (1983a): Strain accumulation in western United States, Ann. Rev. Earth Planet. Sci., 11, 11-43.

SAVAGE, J.C. (1983b): A dislocation model of strain accumu- lation and release at subduction zone, J. Geophys. Res., 88, 4984-4996.

SAVAGE, J.C. (1990): Equivalent strike-slip earthquake cycles in half-space and lithosphere-asthenosphere earth models, J. Geophys. Res., 95, 4873-4879.

Savage, J.C. and W.H. Prescott (1978): Asthenosphere readjustment and the earthquake cycle, J. Geophys. Res., 83, 3369-3376.

SAVAGE, J.C. and W. Thatcher (1992): Interseismic deformation at the Nankai trough, Japan, subduction zone, $J$. Geophys. Res., 97 (in press).

SieH, K., M. Stuiver and D. Brillinger (1989): A more precise chronology of earthquakes produced by the San Andreas fault in southern California, J. Geophys. Res., 94, 603-623.

Stein, R.S., G.C.P. KInG and J.B. RundLe (1988): The growth of geological structures by repeated earthquakes. 2. Field examples of continental dip-slip faults, $J$. Geophys. Res., 93, 13 319-13 331.

THATCHER, W. (1975): Strain accumulation and release mechanism of the 1906 San Francisco earthquake, J. Geophys. Res., 80, 4862-4872.

THATCHER, W. (1983): Nonlinear strain buildup and the earthquake cycle on the San Andreas fault, J. Geophys. Res., 88, 5893-5902.

THATCHER, W. (1984a): The earthquake deformation cycle on the Nankai Trough, southwest Japan, J. Geophys. Res., 89, 3087-3101.

THATCHER, W. (1984b): The earthquake deformation cycle, recurrence, and the time-predictable model, J. Geophys. Res., 89, 5674-5680.

ThATCHER, W. (1986): Cyclic deformation related to great earthquakes at plate boundaries, R. Soc. New Zealand Bull., 24, 245-272.

Thatcher, W. (1990): Present-day crustal movements and the mechanics of cyclic deformation, U.S. Geological Survey Prof. Paper 1515, 189-205.

THATCHER, W. and J.B. RUNDLE (1984): A viscoelastic coupling model for the cyclic deformation due to periodically repeated earthquakes at subduction zones, J. Geophys. Res., 89, 7631-7640.

TST, S.T. and J.R. RICE (1986): Crustal earthquake instability in relation to the depth variation of frictional slip properties, J. Geophys. Res., 91, 9452-9472.

WALCOTT, R.I. (1984): The kinematics of the plate boundary zone through New Zealand: a comparison of short- and long-term deformations, Geophys. J.R. Astron. Soc., 79, 613-633. 